\title{
EDUCAÇÃO INFANTIL, MÍDIAS DIGITAIS E PRÁTICAS EDUCATIVAS: Caminhos cruzados, possíveis diálogos
}

Fernanda Câmpera Clímaco Claudio Marcio Magalhaes ${ }^{(*)}$

\section{INTRODUÇÃO}

A Educação Infantil tem ampliado substancialmente sua presença no bojo das preocupações educacionais no país. Tal preocupação reflete-se nas políticas públicas e nos projetos de ampliação de sua abrangência, com a construção de creches e escolas de Educação Infantil e capacitação dos seus professores. Alheias às angústias dos adultos sobre elas, as crianças, paralelamente, cada vez mais, são apresentadas ao mundo por meio dos novos aparatos digitais, parecendo já terem habilidades inatas para tal. Mas onde essas duas dimensões, a da educação infantil formal e as novas mídias digitais, podem se encontrar? Essa questão e suas consequências são os objetivos da investigação que esse artigo se propõe.

Pretende-se apresentar um panorama conceitual sobre as mídias digitais e suas possíveis associações com as práticas pedagógicas desenvolvidas nas escolas de Educação Infantil. Para tanto, utilizou-se a pesquisa bibliográfica e documental.

A pesquisa bibliográfica trabalhou com os seguintes temas: histórico da educação Infantil, regulamentação da educação infantil e currículo, em nível nacional e em Belo Horizonte/MG, mídias digitais e práticas educativas. A pesquisa documental buscou complementar a pesquisa bibliográfica, a partir do levantamento e análise de leis e documentos voltados para a Educação Infantil, especificamente no município de Belo Horizonte/MG. Para tanto foram observados os seguintes documentos: Lei das Diretrizes e Bases da Educação Nacional, Diretrizes Curriculares Nacionais da Educação Infantil (DCNEI), Referencial Curricular Nacional da Educação Infantil (RCNEI) e as Proposições Curriculares da Educação Infantil (PCEI) de Belo Horizonte/MG.

\footnotetext{
${ }^{(*)}$ Fernanda Câmpera Clímaco. Mestre em Gestão Social, Educação e Desenvolvimento Local pela UNA. Pedagoga, graduada na PUC/MG em 2000. Especialista em Construtivismo e Educação na FLACSO, Argentina, em parceria com a UAM - Universidad de Madrid, concluída em 2004 e pós-graduada em Infância, Cultura e Práticas Formativas, na FUMEC, em 2011. E-mail: fernanda.climaco@gmail.com.

Claudio Marcio Magalhaes. Jornalista, professor universitário, mestre em comunicação social, doutor em educação, professor/orientador do Programa de Pós-Graduação em Gestão Social, Educação e Desenvolvimento Local e do Instituto de Comunicação e Artes do Centro Unviersitário UNA. E-mail: claudiomagalhaes@uol.com.br.
} 
Objetiva-se com esse estudo apresentar a análise das mídias digitais na Educação Infantil em busca de colaborar com a reflexão de um tema presente nas discussões que envolvem as Linguagens digitais nas escolas de E.I.. Para isso, Brito (2011), Carbonell (2002), Carlsson e Von Feilitzen (2002), Melo e Tosta (2008) e Lévy (2010) trazem referências que contribuem com essa reflexão no âmbito da apropriação escolar das novas tecnologias, entre elas, as mídias digitais.

Para tanto, foi realizada uma breve caracterização da Educação Infantil no município de Belo Horizonte/MG, a partir das normas que a regem e sobre a proposta curricular implantada.

Na sequência, discutiu-se o currículo indicado pelas Proposições Curriculares da Educação Infantil de Belo Horizonte/MG e suas linguagens, tendo como foco a linguagem digital, onde se apontaram as possíveis relações com as práticas pedagógicas. Nessa discussão, colaboram Freire (1997), Vigotski (2002) e Gadotti (2007). Por fim, apresentam-se as considerações.

\section{PRÁTICAS EDUCATIVAS E MÍDIAS DIGITAIS NA ESCOLA DE INFÂNCIA}

De fato, muitos ainda questionam qual a necessidade da tecnologia na escola de infância e embora pesquisadores como Ferreira (2009) e Silva (2010), entre outros, tenham demonstrado que estamos diante de uma realidade inquestionável, ainda existem muitas lacunas importantes no que diz respeito à educação infantil. De acordo com Santos (2012), a educação infantil não tem sido foco de estudos quando se trata da utilização de tecnologias em suas práticas, mostrando-se mais impermeável e resistente a essa inovação na prática docente que outros níveis escolares.

Nesse contexto educacional o desafio aumenta, pois é preciso que o professor esteja preparado para o domínio e assimilação crítica da linguagem digital. Assim como afirmam Castro, Fernandes e Lima (2007, p.4):
para que a educação cumpra este papel destacado pelas autoras, faz-se mister que o professor esteja imerso na cultura digital, ou melhor, que esta cultura faça parte do seu processo histórico e de desenvolvimento, ampliando as dimensões do cultural. Para tal, o caminhar faz-se de forma lenta e de acordo com as suas necessidades. Alguns obstáculos diante do novo precisam ser vencidos: o "medo", o domínio técnico e o processo reflexivo sobre a tecnologia.

Gadotti (2007), remetendo-se aos ensinamentos de Paulo Freire (2002), contribui entrelaçando conhecimentos que nos ajudam a compreender que:

\footnotetext{
A educação pode dar um passo na direção deste outro mundo possível se ensinar as pessoas com um novo paradigma do conhecimento, com uma visão do mundo onde todas as formas de conhecimento tenham lugar, se dotar os seres humanos de generosidade epistemológica, um pluralismo de ideias e concepção que se constitui na grande riqueza de saberes e conhecimentos da humanidade. Creio que existe ainda na comunidade humana uma imensa reserva de altruísmo
}

Revista Teias v. 18, n. 50, 2017 (Jul./Set.): Conversas sobre formação de professores, práticas e currículos 
e de solidariedade, um dique que o educador precisa conhecer e potencializar para romper as barreiras do represamento. Educar é empoderar. Mais do que ensinar é preciso reencantar. Ou melhor, ensinar, nesse contexto, é reencantar, despertar a capacidade de sonhar, despertar a crença de que é possível mudar o mundo (GADOTTI, 2007, p. 66).

Essa vontade de fazer diferente e contribuir para um mundo melhor pode gerar experiências pioneiras nas escolas de Educação Infantil e apontar como professores podem vir a ser os agentes dessa transformação. Algumas condições são impeditivas, outras são muito favoráveis a esse ambiente de inovação pedagógica, entre elas, a troca de conhecimentos informais, ligados às práticas cotidianas, às experiências pessoais e a confiança entre os envolvidos, garantindo assim, algo muito importante: as relações de interação.

A partir dessa perspectiva, é possível observar o quanto as interações têm papel fundamental no desenvolvimento da mente. Pois, é a partir da interação entre diferentes sujeitos que estabelecem os processos de aprendizagem e, por consequência, o aprimoramento de suas estruturas mentais existentes desde o nascimento.

Diante disso, a cibercultura de Lévy (2010) e suas ferramentas de comunicação social também contribuem no contexto educacional sobremaneira para a promoção da interação. Porém, o que chama a atenção nos estudos do autor são suas posições sobre a nova relação que o sujeito estabelece com os saberes:

O que é preciso aprender não pode mais ser planejado nem precisamente definido com antecedência. (...) Devemos construir novos modelos do espaço dos conhecimentos. No lugar de representação em escalas lineares e paralelas, em pirâmides estruturadas em 'níveis', organizadas pela noção de pré-requisitos e convergindo para saberes 'superiores', a partir de agora devemos preferir a imagem em espaços de conhecimentos emergentes, abertos, contínuos, em fluxo, não lineares, se reorganizando de acordo com os objetivos ou os contextos, nos quais cada um ocupa posição singular e evolutiva (LÉVY, 2010, p. 168).

Nesse sentido, o autor coloca em cheque toda a organização do sistema educacional, isso quer dizer também sobre os currículos e o papel do professor. O professor deveria abandonar o lugar historicamente construído de detentor do conhecimento para se tornar um incentivador da inteligência coletiva.

A princípio, nas escolas de E.I., as crianças e os adultos interagem numa relação social específica, a relação de ensino-aprendizagem. Sua finalidade, que é a de ensinar e aprender, está explícita aos seus integrantes, que nessa relação ocupam lugares sociais distintos: a criança, no papel do aluno e o adulto, no de professor. 
Sendo assim, acredita-se que o professor deve se apropriar das inovações junto ao aluno, deixando para trás uma postura distante, a de um ser inalcançável de outros tempos, para agora estar junto à criança. Esta nova postura proporcionará uma via de mão dupla, do docente para a criança e vice-versa. Resultando ao longo dos processos de ensino e aprendizagem, em uma construção eficiente de saberes coletivos, compartilhados e, dessa forma ambos se informam e constroem conhecimento.

Nesse sentido, motivada pela escola e pelo convívio com os colegas, a criança entende que o mundo deve ser buscado e não se pode esperar que ele seja oferecido, tanto pela escola quanto pela orientação familiar, como se praticava antes. Conforme o mesmo autor, associado ao avanço de uma pedagogia menos conservadora, em que a criança deixa de ser um simples depositário de informações, atualmente, o incentivo é pela busca ao conhecimento já nos primeiros anos escolares, nos quais as fontes primárias são os próprios meios de comunicação (em detrimento das tradicionais enciclopédias e livros didáticos). As crianças, naturalmente ávidas curiosas por tudo o que as cerca, são incentivadas cada vez mais a se apropriar do mundo pela mídia. (MAGALHÃES, 2007, p. 78-79).

Sendo assim, os docentes devem reconhecer essa criança como um nativo digital, considerando novas formas de mediação no ensino. Nesse sentido, com o objetivo de aliar-se às práticas pedagógicas, o uso das mídias digitais pode colaborar com o professor de E.I. nesse processo de mudança de postura profissional, bem como a assumir uma nova postura frente às tecnologias que surgem a todo momento na sociedade.

No caso das escolas, como instrumentos para alcançar as propostas educativas de linguagem digital do currículo, são diversos os tipos de equipamentos digitais disponibilizados aos docentes: vídeos, aparelhos de DVD, computadores, filmadoras, câmeras fotográficas digitais, internet, gravadores, projetores de slides, datashow, impressoras, tvs, entre outros recursos.

Neste sentido, os processos lineares, pelos quais o educador está acostumado, são desafiados, uma vez que essas possibilidades oferecem novos pontos de contato e técnicas de interação. "Cada uma dessas técnicas específicas facilita determinados procedimentos de linguagem e ajuda a criar novos objetos estéticos" (CANNITO, 2010, p. 73). Sendo assim, o professor se vê diante de um aparato tecnológico, com o qual precisa interagir e, a partir daí, criar experiências educativas inovadoras para/com as crianças. Crianças que também não são como as de antigamente, trata-se agora, de nativos digitais, na escola de E.I..

Dessa forma, instauram-se aqui alguns entraves, onde Gadotti (2007) reafirma essa questão em sua discussão ao sugerir a idealização do professor, mas ele próprio, a seguir nos aponta caminhos: 
Concordo: o cenário não é otimista. Eu não poderia, de forma alguma, ignorá-lo. Ao contrário, precisamos reacender o sonho de ser professor justamente para combater esse estado de coisas. Sair do plano ideal para a prática não é abandonar o sonho para agir, mas agir em função do sonho, agir em função de um projeto de vida e de escola, de cidade, de mundo possível, de planeta... um projeto de esperança. (GADOTTI, 2007, p. 67).

O caminho para mudar não é fácil. É preciso superar os desafios se realmente o que se busca é uma educação que faça sentido com seu tempo, suas tecnologias, seus referenciais, sua vida.

Conforme Melo e Tosta (2008), é uma questão manter as práticas pedagógicas atualizadas e sintonizadas com nossa realidade social. São muitos os novos processos de troca de informação e produção de conhecimentos e não é tarefa fácil a incorporação dessas novas tecnologias na escola. E não é o caso utilizar as mídias digitais a qualquer custo.

Para tanto é preciso fomentar a pesquisa, suscitando ideias e propostas para a superação do descompasso entre educação e utilização das mídias, instrumentalizar escolas com as tecnologias possíveis e a partir delas, incentivar programas de formação docente continuada com socialização de práticas exitosas a fim de estimular e inspirar os docentes a experimentar tais posturas em sua realidade educativa com as crianças.

De acordo com Melo e Tosta (2008), se, a partir da escola, a criança tiver acesso a instrumentos mais especializados, como uma educação para lidar com a tecnologia comunicacional, se ela tiver maiores oportunidades de expressão e desenvolvimento de suas habilidades comunicativas, seguramente estará formando um sujeito mais bem preparado capaz de tomar decisões frente às mensagens midiáticas recebidas.

Nesse sentido, é importante considerar que as mudanças culturais provocadas pelas mídias digitais na escola devem ser compreendidas em um contexto que favoreça ou não seu sucesso, sempre em relação a algo. Melo e Tosta (2008) acreditam que é nessa perspectiva que a apropriação e uso dos bens produzidos pelas mídias passa pela compreensão de que tal processo é mediado pelo contexto cultural em que ela ocorre. Ou seja, na escola, a mídia deve atuar como mediadora de possíveis aprendizagens, ser mais uma importante linguagem de expressão e comunicação de conhecimentos e não ser, apenas, instrumentos aos quais professores e alunos utilizam passivamente. 


\section{Mídias digitais e educação infantil: diálogos em construção}

Embora os autores estejam pelo mundo afora, há algumas semelhanças conceituais. Sem querer correr o risco de uma generalização, observam-se tendências que parecem ser comuns nos artigos e estudos sobre a mídia-educação.

A utilização de tecnologias e mídias digitais tem deixado muitos educadores de E.I. à deriva, sem saber o que e como fazer, à medida que os departamentos de tecnologia e salas de informática de muitas escolas tendem a dominar os discursos de tecnologia.

Se o desejável é que os professores incorporem tecnologias digitais à prática pedagógica, transformando-a para melhor integrá-las no contexto escolar, é preciso ir além. De acordo com Freitas (2010), os professores precisam compreender os gêneros discursivos e linguagens digitais que são usados pelos alunos, para integrá-los, de forma criativa, construtiva e contextualizada ao cotidiano escolar. Integrar, não significa abandonar práticas existentes, que são produtivas e necessárias, ao contrário, implica que a elas se acrescente o novo.

Nesse sentido, conforme a autora, é imprescindível que professores e alunos sejam letrados digitais, isto é, que professores e alunos apropriem-se criativa e criticamente da tecnologia, atribuindo-lhe significados e funções, em vez de apenas consumi-la passivamente. Espera-se que o letramento digital seja compreendido para além de um uso meramente técnico e instrumental.

Diante desse contexto, diversos autores tais como Lankshear, Snyder e Green (2000), Buzato (2006) e Souza (2007), apresentam um conceito que pode ser uma luz no fim do túnel para a formação docente. Letramento Digital (Digital Literacy), o conceito em questão tem sido bastante discutido no mundo e no Brasil, por pesquisadores do tema. Por aqui, conforme afirmação de Buzato (2006),

letramentos digitais (LDs) são conjuntos de letramentos (práticas sociais) que se apoiam, entrelaçam e apropriam mútua e continuamente por meio de dispositivos digitais para finalidades específicas, tanto em contextos socioculturais geograficamente e temporalmente limitados, quanto naqueles construídos pela interação mediada eletronicamente. (BUZATO, 2006, p. 16).

Em outras palavras, compreende-se letramento digital como o conjunto de competências e habilidades necessárias para que o sujeito compreenda e utilize a informação de maneira crítica e construtiva, de variadas formas, vinda de variadas fontes e apresentada por diferentes meios digitais.

De acordo com Souza (2007), ser letrado digital inclui, além do conhecimento funcional sobre o uso da tecnologia, um conhecimento crítico desse uso. Assim, para o docente, tornar-se digitalmente letrado significa desenvolver novas habilidades, aprender novos tipos de discursos e, 
segundo a autora, por vezes, assemelha-se até a aprender outra língua. Trata-se de um desafio aos docentes da atualidade e aos que estão porvir.

Nesse sentido, compreende-se que o letramento digital possa fazer parte de um projeto de formação docente nas escolas de E.I. não como uma disciplina isolada, mas enquanto linguagem presente em práticas interdisciplinares, nas quais o docente experiencie o letramento digital constituindo, assim, o próprio processo de formação profissional. Segundo Buzato (2006):

Se aceitarmos que os letramentos digitais, as práticas, tecnologias e significados que os constituem não estão separados por uma "brecha" das práticas, tecnologias e significados que nos trouxeram até aqui, mas, ao contrário, são o fruto de uma ação social coletiva que gerou apropriações, amalgamamentos e sínteses entre gêneros, linguagens e tecnologias até então vistas como coisas separadas, estaremos em posição de começar a pensar uma lógica de formação do professor que não é do tipo "agora isso e não mais aquilo", mas do tipo "transformar isso praticando aquilo". (BUZATO, 2006, p.19).

Conforme Freitas (2010), isso é importante, uma vez que, nos processos formativos de professores, tanto iniciais quanto continuados, ainda se mostram tímidos os esforços de trabalho relacionados ao letramento digital. É necessário que a escola, por mais desafiador que pareça, assuma essas novas possibilidades de transformação e inicie esse processo de mudança.

Castro, Fernandes e Lima (2007) reforçam que a solução para vencer os desafios no uso da tecnologia é a prática reflexiva, que oferece bases teóricas para facilitar a compreensão dos processos em jogo e a si mesmo, abrindo na própria escola espaços para a discussão e troca de experiências entre os professores.

Sendo assim, compreendemos que as instituições escolares, de modo geral e em especial, as de E.I., estão incorporando em seu contexto a utilização cada vez mais frequente de tecnologias, acreditando serem elas, "facilitadoras" do trabalho docente. Uma justificativa para isso se deve ao fato de que a criança enxergará uma aproximação entre a escola e sua realidade fora dela.

Considerando que essa afirmativa é importante para a presença das mídias digitais na escola, entendemos que práticas com essa premissa precisam avançar para um diálogo onde se estabeleçam reflexões qualificadas, contextualizadas e sistematizadas com a realidade das escolas e salas de aulas. Mas como fazer? O sentimento é que professores estão à deriva nesse mar de novas tecnologias e informações. Ficar assim não é possível. É preciso enxergar possibilidades, traçar rotas objetivas, ter escuta apurada das demandas das crianças, ver modelos e buscar mediadores eficientes na construção de novas aprendizagens a partir da utilização das mídias digitais. Conforme Protásio e Albuquerque (2004) 
ao pensar em uma proposta educativa para as crianças pequenas, é essencial reconhecê-las como sujeitos co-construtores, ricos em potencial, inteligentes e competentes. Este é o grande desafio para nós, educadores, professores, profissionais da educação: ouvir as crianças e compreender suas culturas para então pensarmos em uma proposta educativa baseada nas relações estabelecidas com elas. (PROTÁSIO E ALBUQUERQUE, p. 102, 2004).

Nesse sentido, é preciso que a escola faça, segundo Melo e Tosta (2008), uma reflexão que implica que o debate sobre a mídia seja apropriado no projeto político pedagógico (PPP) das instituições de ensino. Em outras palavras, que sejam inseridas no cotidiano escolar, as linguagens das mídias como objeto de estudo e reflexão por parte dos gestores, professores e toda a comunidade escolar.

Uma possível alternativa é buscar caminhos de integração entre a prática escolar e a utilização das mídias digitais de forma significativa e contextualizada, em contrapartida às ações educativas fragmentadas, mecânicas e sem sentido para as crianças. Além disso, de acordo com Melo e Tosta (2008), à escola cabe, além de educar o aluno no sentido de torná-lo receptor crítico, formar o professor, apropriador crítico de linguagens, seja em termos de conteúdo ou de tecnologias. Nesse sentido, a importância de uma formação continuada, prática, reflexiva e em serviço serve como um norteador, um caminho a ser seguido.

O que se espera dentro de uma nova perspectiva curricular é que ocorra uma superação dessa postura fragmentada e sem sentido. Acredita-se que a utilização da mídia-educação pode contribuir sobremaneira num processo de ensino-aprendizagem onde haja uma abordagem construtiva, reflexiva e compartilhada entre professores, crianças e comunidade na utilização das mídias digitais na escola de infância e dessa maneira produzir aprendizagens realmente significativas.

\section{AS POLÍTICAS PÚBLICAS PARA INFÂNCIA EM BELO HORIZONTE}

De acordo com a Proposta Curricular da Educação Infantil de Belo Horizonte (PCEI), a ampliação das creches comunitárias, filantrópicas e/ou confessionais no município (de Belo Horizonte) aconteceu por volta do final da década de 1970 (nos arredores da capital), em sua região metropolitana. Porém, paralelo ao surgimento dessas instituições, observou-se também aumento na situação de pobreza da população.

O caráter assistencial e a emergência do atendimento, muitas vezes, significava ter creches que funcionavam em condições inadequadas, em locais improvisados, sem materialidade ou profissional habilitado. Entretanto, essa era a única forma de atendimento às famílias que 
necessitavam garantir inserção no mercado de trabalho, visando seu sustento. (PCEI, p. 25, 2014).

Conforme as PCEI de Belo Horizonte (2014), surgiram vários movimentos sociais em Belo Horizonte, entre eles, o Movimento de Luta Pró-Creche (MLPC). Institucionalizado legalmente em 1986, o movimento tinha como objetivo lutar pelos direitos das crianças, bandeira esta que defende até os dias atuais. Atualmente, o MLPC é quem representa junto à prefeitura de $\mathrm{BH}$ as creches que atendem às crianças do município de zero a cinco anos.

A legislação nacional, nas últimas décadas, tem contemplado a Educação Infantil, a partir da promulgação da Constituição Federal de 1988 (art. 208, inciso IV), na importante aprovação da Lei das Diretrizes e Bases da Educação Nacional (Lei 9.394/96), no PNE (Plano Nacional de Educação) e no Referencial Curricular Nacional de Educação Infantil (BRASIL, 1998).

Nestes documentos, a E.I. vem sendo considerada um dos instrumentos necessários para dar início a uma educação de qualidade e aos processos de ensino e aprendizagem das crianças pequenas. Não podemos negar que houve avanços na área da educação da infância, com a elaboração do Referencial Curricular Nacional da Educação Infantil (RCNEI), em 1998, pois, até então, não existia nenhum tipo de orientação sobre E.I. em âmbito federal.

A crítica mais forte ao RCNEI, de acordo com Cerizara (2000), se deu ao fato do documento não ter tido a participação desejada dos atores sociais em sua elaboração, este foi, sem dúvida, um avanço importante nos processos constituintes da E.I. no País. Dessa maneira, as crianças passaram a ter o reconhecimento de uma escola apropriada para elas, como local de aprendizagens planejadas, com um currículo próprio e com profissionais preparados para executar as práticas educativas para a infância.

Lucas (2005) ainda afirma que, se antes lhes era ofertado qualquer espaço com um adulto cuidador para ficarem enquanto seus pais trabalhavam, hoje os pequenos começaram a ter sua individualidade e seus direitos respeitados. O espaço dedicado a elas não só deve garantir seu cuidar, bem como o educar. A assistência à saúde e a educação passaram a ser compreendidas como direitos sociais de todas as crianças.

Ainda de acordo com a LDBEN, é responsabilidade da União estabelecer, em colaboração com Estados e Municípios, as proposições e diretrizes curriculares que nortearão o trabalho pedagógico. Entretanto, são os municípios que devem garantir o atendimento. Dessa forma, de acordo com a LDBEN no art. II do título é determinado que: 
Os municípios incumbir-se-ão de V- oferecer a educação infantil em creches e pré-escolas e, com prioridade, o ensino fundamental, permitida a atuação em outros níveis de ensino somente quando estiverem atendidas plenamente as necessidades de sua área de competência e com recursos acima dos percentuais mínimos vinculados pela Constituição Federal à manutenção e desenvolvimento do ensino. (BRASIL,1996).

A implementação das políticas públicas propostas para as Unidades Municipais de Educação Infantil (UMEIs) em Belo Horizonte visa garantir o direito de acesso de todas as crianças à Educação Infantil, conforme as metas previstas no Plano Nacional de Educação (PNE 2014-2024):

Meta 1 - Universalizar, até 2016, o atendimento escolar da população de 4 e 5 anos, e ampliar, até 2020, a oferta de educação infantil de forma a atender a 50\% da população de até 3 anos.

Meta 4 - Universalizar, para a população de 4 a 17 anos, o atendimento escolar aos estudantes com deficiência, transtornos globais do desenvolvimento e altas habilidades ou superdotação na rede regular de ensino. (BRASIL, 2014).

De acordo com Silva (2002), o Sistema Municipal de Ensino em Belo Horizonte foi instituído em 1998 e os membros do Conselho Municipal de Educação tiveram a tarefa de elaborar, em consonância com as orientações de universalização da Educação Infantil, a resolução que orientou o processo de autorização e funcionamento das instituições de Educação Infantil em Belo Horizonte - Resolução nº 001/2000. A resolução entrou em vigor em 7 de novembro de 2000.

Essa resolução sofreu alterações relativas à adequação dos espaços, das instalações e dos equipamentos, definiu o processo de autorização de funcionamento, credenciamento, supervisão e responsabilidades das instituições de ensino e, principalmente, o direito à educação e o dever de educar, conforme o disposto em seu artigo primeiro:

Art. $1^{\circ}$. A Educação Infantil, primeira etapa da Educação Básica, constitui direito da criança de 0 (zero) a 6 (seis) anos ao cuidado/educação a que o Estado tem o dever de atender, complementando a ação da família e da comunidade (BELO HORIZONTE, 2000).

Para atender às demandas da sociedade e promover as crianças o acesso à educação de qualidade, criou-se, por meio da Lei Municipal 8.679/2003, o Programa Primeira Escola (BELO HORIZONTE, 2003).

Sabe-se que a demanda é muito maior que a oferta, são centenas de crianças entre 0 e 5 anos sem atendimento digno garantido e, sendo assim, o Município ainda precisa efetivar políticas públicas que contribuam para que todas as crianças do município consigam ter garantidos os seus direitos ao cuidado e à educação.

Garantir que todas as crianças entrarão na escola aos quatro anos não quer dizer que a educação vai melhorar.

Revista Teias v. 18, n. 50, 2017 (Jul./Set.): Conversas sobre formação de professores, práticas e currículos 
É preciso pensar em toda a rede e no bem-estar do aluno. E a escola precisa ter estrutura, não só em relação ao espaço físico e materialidade. É preciso investir na reflexão, estudo e formação docentes, na construção de um Projeto Político-Pedagógico (PPP) e currículo que priorizem a criança e a infância. Nesses novos tempos, há ainda novos desafios como: capacitar essas novas unidades, e as que estão porvir, de interfaces com as novas formas midiáticas e digitais de apropriação do mundo.

\section{Um currículo para os pequenos}

Tratar do currículo na contemporaneidade pressupõe a observação de diversos autores como Demo (1993), Zabala (1998), Forquim, (1999), Sacristán (2000), Moraes (2003) Gadotti (2007), que se dedicam a pensar e compreender o termo, buscando definições e enfoques antropológicos, sociológicos, ideológicos e culturais. Suas contribuições nos ajudam na constituição de um conceito dinâmico sobre currículo.

Sacristán (2000), por exemplo, vê no currículo uma forma de se ter acesso ao conhecimento, e que por isso não se pode esgotar seu significado em algo rígido e estático. Deve-se pensar por meio das condições em que o currículo se realiza e se converte numa maneira particular de entrar em contato com a cultura.

Historicamente, as sociedades geraram uma crescente necessidade de "especialização" dos saberes, o que refletiu na educação em uma forma de organizar os conhecimentos compartimentados, separados por áreas e disciplinas, na maioria das vezes, isoladas entre si (MORAES, 2003). Essa fragmentação dos saberes, durante muito tempo fez e ainda faz parte da cultura escolar. No sentido de ampliar a discussão, em sua crítica ao currículo, Forquin (1999) argumenta que o mesmo é apenas um

(...) conjunto de conteúdos cognitivos e simbólicos que selecionados, organizados, normalizados, rotinizados, sob o efeito de imperativos de didatização, constitui habitualmente o objeto de uma transmissão deliberada no contexto das escolas, (FOURQUIM, 1999, p. 167).

Nesse sentido, de acordo com o autor, essa organização curricular imposta desfavorece o trabalho de reordenação e reestruturação para tornar os conteúdos assimiláveis pelos alunos. Essa organização, muitas vezes, é feita por profissionais especialistas e não conta com a participação de professores, alunos e comunidade. De acordo com Moraes (2003), essa forma de organização gera um tipo de saber, também fragmentado. Em contrapartida, já existem em nossa sociedade movimentos de estudiosos e profissionais que buscam superar esse modelo curricular tecendo propostas que dialogam com demandas atuais, que visam integração, interdisciplinaridade e aprendizagem em redes. 
Quando se obedece somente às prescrições políticas, corre-se o risco de homogeneizar e engessar processos criativos, deformando a ideia que se traz de um currículo aberto, interdisciplinar e crítico. Sacristán (2000) confirma que:

este é um aspecto especifico da política educativa que estabelece a forma de selecionar, ordenar e mudar o currículo dentro do sistema educativo, tornado claro o poder e a autonomia que diferentes agentes têm sobre ele, intervindo, dessa forma, na distribuição do conhecimento dentro do sistema escolar e iniciando na prática educativa, enquanto apresenta o currículo seus consumidores, ordenam seus conteúdos e códigos de diferentes tipos. (SACRISTAN, 2000; p 109).

Portanto, essa é a visão que se pretende superar. Conforme afirma Gadotti (2007) é preciso enxergar além do que está posto. No Brasil, a realidade é ainda muito diferente, pois a alienação social e o "descompromisso" diante da educação são fatos lastimáveis.

A exemplo do disposto no documento Indagações sobre o Currículo MEC (2006),

é fundamental desenvolver a consciência de que os currículos são conteúdos não prontos a serem passados para os alunos. São uma construção e seleção de conhecimentos e práticas produzidas em contextos concretos e em dinâmicas sociais, políticas e culturais intelectuais e pedagógicas. Conhecimentos e práticas expostos às novas dinâmicas e reinterpretados a cada contexto histórico (MEC, 2006, p. 9).

Baseado nessas concepções que enxergam o currículo como uma construção coletiva, as Proposições Curriculares para a Educação Infantil da SMED/PBH (Secretaria Municipal de Educação de Educação) de Belo Horizonte apresentam essa concepção que propõe que o

currículo seja compreendido como um caminho, elaborado e traçado solidariamente pelos atores do processo educativo. Sendo um caminho, ele se constitui durante a trajetória daqueles que o percorrem. O currículo se concretiza e se ressignifica durante a caminhada daqueles que estão no cotidiano das vivencias escolares de um contexto educacional específico. (...) As Proposições Curriculares para a Educação Infantil de Belo Horizonte, constituem-se também em uma escolha. Uma opção clara deste município pelas concepções, princípios, conhecimentos, procedimentos e atitudes que devem orientar e organizar as experiências educativas das instituições de Educação Infantil (BELO HORIZONTE, 2014, p.46).

Este currículo é nomeado pela SMED, de Proposições Curriculares para Educação Infantil (PCEI). De acordo com as PCEI (BELO HORIZONTE, 2014), considerando as discussões realizadas na Rede de Formação entre 2007 e 2008 e confirmado pelas DCNEI (BRASIL, 2010), compreende-se a criança como centro do processo educativo. Conforme consta no documento, entende-se que: 
a criança no centro estabelece interações com o mundo (cultura-sociedade-natureza) desde que nasce, interrogando-o, investigando-o, buscando conhecê-lo e tendo no brincar sua principal forma de compreensão e manifestação no mundo (BELO HORIZONTE, 2014, p.47).

Tal concepção vai ao encontro de autores como Vigotski (2002) quando acrescenta que o que a criança necessita na escola, além de uma interação compartilhada com os adultos, é de oportunidades que auxiliem na construção de novos conceitos e aprendizagens, sejam elas dadas pelo professor, por outras crianças e/ou pelas relações que se dão a partir daí. Para Vigotski (2002):

Desde os primeiros dias do desenvolvimento da criança, suas atividades adquirem um significado próprio num sistema de comportamento social e, sendo dirigidas a objetivos definidos, são refratadas através do prisma do ambiente da criança. O caminho do objeto até a criança e desta até o objeto passa através de outra pessoa. Essa estrutura humana complexa é o produto de um processo de desenvolvimento profundamente enraizado nas ligações entre história individual e história social (VIGOTSKI, 2002, p. 54).

Nesse sentido, conforme o referido autor, o percurso do desenvolvimento humano se dá "de fora para dentro" e é marcado pela inserção do sujeito em determinado grupo sociocultural. Há múltiplas interações no processo de elaboração conceitual infantil e a escola, ao adotar um currículo que tem como foco a criança e seu desenvolvimento como um todo, adquire oportunidade de repensar sua postura.

Dessa maneira, entende-se que se pode e se deve sempre utilizar novas estratégias, instrumentos e outras formas de mediação nessa complexa relação que as crianças estabelecem na construção de suas aprendizagens.

Essas novas estratégias parecem estar presentes nas PCEI e apresentam-se formatadas em três grandes eixos: Natureza, Cultura e Sociedade e em sete linguagens: Corporais, Orais, Musicais, Matemáticas, Escritas, Plástico-visuais e, por fim, nosso objeto de estudo, as Linguagens Digitais (Fig. 1).

\section{FIGURA 1. PCEI 2014}

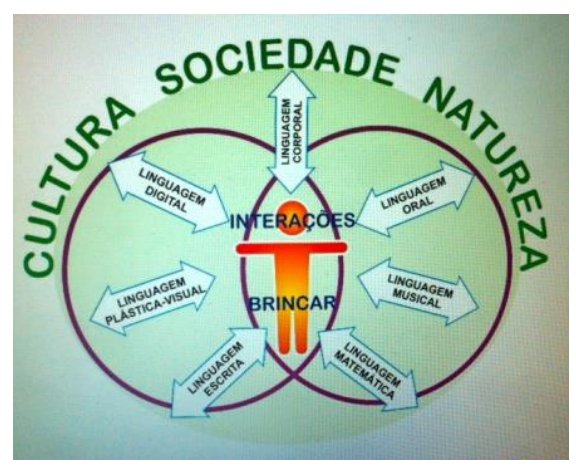

Fonte: Secretaria Municipal de

Fducarão de RH 7014

${ }^{1}$ http://portalpbh.pbh.gov.br, acesso em 16 de março de 2015

Revista Teias v. 18, n. 50, 2017 (Jul./Set.): Conversas sobre formação de professores, práticas e currículos 
A partir desse novo cenário, conforme Melo e Tosta (2008), a escola, enquanto instituição formadora, e os professores, enquanto agentes dessa formação, assumem juntos a grande responsabilidade em relação à mídia na escola e para a escola. O fato do tema em questão ter sido contemplado em currículo aparenta uma grande conquista e aponta que as circunstâncias parecem favoráveis. Mas não é essa a realidade que se vive.

Diante desta perspectiva, caracterizam-se como dificultadores a falta de capacitação profissional, de equipamentos e estrutura física adequada, além das dificuldades em concretizar o currículo no cotidiano escolar.

Atualmente, existem muitos referenciais à disposição dos professores (Diretrizes Curriculares Nacionais, Referencial Curricular Nacional da Educação Infantil) para definir sobre quais conteúdos ensinar e o que é esperado que as crianças aprendam em cada faixa etária. Dessa maneira, numa tentativa de solucionar essa questão, desde a aprovação do Plano Nacional de Educação (2014/2024), o MEC convocou pesquisadores, formadores de professores e representantes de associações como a União Nacional dos Dirigentes Municipais de Educação (Undime) e a Associação Nacional de Pós-Graduação e Pesquisa em Educação (Anped) para a construção de um referencial nacional que responda a essa demanda e estão sendo discutidas na Base Nacional Curricular Comum (BNCC) (DURLI; COSTA E SANCHES, 2015).

O Plano Nacional de Educação determina que até junho de 2016, a BNCC seja encaminhada ao Conselho Nacional de Educação (CNE). Em setembro de 2015 a versão preliminar da BNCC foi disponibilizada no site $^{2}$ e aberta à consulta pública onde todo cidadão e instituição poderiam opinar por meio de uma plataforma digital. Muitos órgãos e entidades enviaram suas contribuições para a elaboração do documento.

Dentre todos os conteúdos curriculares abordados na proposta de reformulação do BNCC, nos interessa o que trata da questão da linguagem digital. Dentre as diversas reivindicações nesse campo, a Associação Brasileira de Televisão Universitária (ABTU) se posicionou da seguinte forma:

A pedagogia da Mídia-Educação deve dar preferência a projetos que agreguem o enorme capital de conhecimentos tecnológicos que o aluno já traz, assim como a sua própria produção midiática, com a tutoria do professor no desenvolvimento de competências e habilidades que possam construir o conhecimento para a leitura social, e não só operacional, das diversas manifestações midiáticas, assim como na produção de textos e roteiros, a interpretação da publicidade, o uso social dos diversos aparatos tecnológicos, entre outros (ABTU, 2015, p. 6).

\footnotetext{
${ }^{2}$ basenacionalcomum.mec.gov.br
} 
Nesse sentido, o que se espera é a superação de uma visão utilitarista das diversas mídias disponíveis nas instituições. Sendo assim, faz-se urgente fomentar essa reflexão para uma aplicação mais crítica e contextualizada dessa linguagem no contexto escolar. Insistentemente, propõem-se investimentos em formação docente com foco nos instrumentos e conteúdos midiáticos. A partir dessas mudanças, o cenário que se descortina, pode significar tanto uma real oportunidade de mudança, quanto um retrocesso que diz respeito às relações entre as práticas educativas e a utilização de mídias no ensino brasileiro.

\section{CONCLUSÃO}

Com o avanço cada dia mais rápido das tecnologias, novas demandas educativas avançam para o território da educação infantil e reverberam-se nas escolas e nas práticas pedagógicas, que se aventuram no campo das mídias digitais.

Se, por um lado, num esforço em acompanhar o desenvolvimento das sociedades, as escolas de infância incorporam em suas propostas e currículos a utilização da Linguagem Digital, por outro, professores sentem-se impotentes para lidar com essa mudança. Municípios e instituições responsáveis por essa etapa de ensino se veem diante de mais uma provocação, que é o da formação docente com foco na utilização não somente das tecnologias, mas também das mídias digitais.

Práticas educativas que utilizam as mídias digitais têm o poder de dar visibilidade a diferentes formas culturais que fazem parte de um território e que não constam nos livros.

Por isso, a importância de reivindicar a participação dos professores e das famílias, não enquanto tais, mas enquanto cidadãos e cidadãs.

Dessa maneira, o trabalho educativo deve ultrapassar os muros e convocar toda a comunidade a participar e compartilhar o que está acontecendo nas escolas. Compartilhar, nesse sentido, não é divulgar nas redes sociais para as pessoas “curtirem”, mas sim, ser parte, integrar, fazer junto ao professor e às crianças.

Uma hipótese relevante a ser desenvolvida a partir das contribuições das diversas práticas democráticas, e a que nos lembra, de algum modo, que a escola pública não é do Estado, nem dos professores, nem dos pais, mas de toda a comunidade. E esta, por sua vez, tem o direito de participar e de intervir no controle do serviço público de ensino. Nesse sentido, o empoderamento e a participação da comunidade ganham sentido. 
Além de contribuir na quebra de preconceitos que invalidam práticas pedagógicas que utilizam as mídias digitais na Educação Infantil e incentivar a reflexão das práticas pedagógicas digitais e suas influências no processo de ensino-aprendizagem, toda a comunidade escolar deve, portanto, tomar parte dos processos que permeiam sua comunidade. As mudanças provocadas pelas tecnologias levarão tempo para serem assimiladas pela sociedade, já que elas implicam em uma nova postura e a escola pode ser a instituição a iniciar esse debate.

Contudo, cabe dizer que se compreende que o compromisso social de uma pesquisa é também apresentar contribuições para que o campo observado possa nutrir-se dos debates que suscita, colocando em permanente discussão o sentido daquilo que se produz.

Assim, esse trabalho se propôs a contribuir no âmbito educacional, apresentando uma breve discussão sobre utilização de mídias digitais nas práticas educativas na E.I. Identificaram-se caminhos ora cruzados, ora distintos, rumo ao mesmo destino: o desafio em propor uma educação para as crianças que acompanhe as mudanças sociais e se integre a elas através da utilização de recursos midiáticos, de maneira crítica, criativa e construtiva.

Por fim, observando a importância que as perguntas assumem no decorrer da presente reflexão, o referencial teórico apresenta mais alguns questionamentos, mantendo as inquietações que conduziram a pesquisa: como estão acontecendo as práticas de ensino-aprendizagem oriundas de diferentes concepções pedagógicas e mediadas pelas tecnologias digitais? Como professores estão se capacitando? Pode-se considerá-las práticas pedagógicas inovadoras? Siga-se em busca de respostas. 


\section{REFERÊNCIAS}

ASSOCIAÇÃO BRASILEIRA DE TELEVISÃO UNIVERSITÁRIA (ABTU). Contribuições para a BNCC. Disp.: <http://www.abtu.org.br/WebSite/wp-content/uploads/2015/12/ABTU-Contribuicoes-ao-BNCC.pdf〉. Acesso: 15 já. 2016.

BELO HORIZONTE. Conselho Municipal de Educação. Resolução 01/2000. Fixa normas para a educação infantil no âmbito do Sistema Municipal de Ensino de Belo Horizonte. Belo Horizonte: CME/BH, 07 nov. 2000.

. Lei 8.679, de 11 nov. 2003. Cria as unidades municipais de educação infantil e o cargo de Educador Infantil. Diário Oficial do Município, Belo Horizonte, 2003.

Proposições Curriculares para a Educação Infantil. Belo Horizonte, 2014. Disp.: 〈http://portalpbh.pbh.gov. br>. Acesso em 15/12/2015.

Sistema de Gestão Escolar (SGE). Secretaria Municipal de Educação de Belo Horizonte. SMED/PBH. Disp.: <http://portalpbh.pbh.gov.br>. Acesso em 15/11/2015.

2016.

Plano De Metas Da Atual Gestão Municipal. Disp. <http://Portalpbh. Pbh.Gov.Br/Pbh>. Acesso em: 02 fev,

. Lei 8.069, 13 jul. 1990. Estatuto da Criança e Adolescente - ECA. Diário Oficial da União. Poder Legislativo, Brasília, 16 jul. 1990, Seção I, p. 13.563.

. Lei 9.394, de 20 dez. 1996. Estabelece as Diretrizes e Bases da Educação Nacional. Diário Oficial da União, República Federativa do Brasil, Brasília, DF, 23 dez. 1996.

MEC/SEB. Referencial Curricular Nacional da Educação Infantil. Brasília: MEC, 1998.

MEC/SEB. Política Nacional de Educação Infantil: pelo direito das crianças de zero a seis anos à educação. Brasília : MEC, 2006.

. MEC/SEB. Diretrizes curriculares nacionais para a educação infantil. Brasília: MEC, SEB, 2010.

. MEC. Plano Nacional de Educação - Decênio 2011- 2020.2014 Disp.: <http://portal.mec.gov.br/arquivos/ pdf/pne.pdf>. Acesso em 20/02/2015.

BRITO, Gláucia da Silva. Educação e novas tecnologias: um repensar. Curitiba, Ed. Intersaberes, 2011.

BUZATO, M. E. K. Letramentos digitais e formação de professores. São Paulo: Portal Educarede. 2006. Disp.: <http://pitagoras.unicamp.br/ teleduc/cursos/diretorio/tmp/1808/ portfolio/item/61/LetramentoDigital_MarceloBusato.pdf>. Acesso em: 13 fev. 2016.

CANNITO, Newton Guimarães. A televisão na era digital: interatividade, convergência e novos modelos de negócios. São Paulo: Summus, 2010.

CARBONELL, Jaume. A aventura de inovar: a mudança na escola. Trad. Fátima Murad. Porto Alegre: Artmed, 2002. CARLSSON, Ulla; FEILITZEN, Cecilia Von. A criança e a mídia: Imagem, Educação e Participação. São Paulo: Cortez, 2002.

CARVALHO, M. S. Educação Infantil pós-LDB: rumos e desafios. Campinas: Autores Associados, 2003. p. 19-49.

CASTRO, Ana Paula Pontes; FERNANDES, Olívia Paiva; LIMA, Yara Porto de. Inserção do professor no universo digital: desafios do processo. Teias. Rio de Janeiro, ano 8, n. 15-16, jan./dez. 2007.

CERISARA, A.B. A produção acadêmica na área da educação infantil a partir da análise de pareceres sobre o Referencial Curricular Nacional da Educação Infantil. In: FARIA, A.L.G.; PALHARES, M.S. (Org.). Educação infantil pós-LDB: rumos e desafios. Campinas: Autores Associados, 2000. p.19-49. Polêmica do nosso tempo, 62.

COELHO, Patrícia M.F. Os nativos digitais e as novas competências tecnológicas. PUC/SP. Tese (Pós doutoramento) - Universitat de VIC/ESPANHA, 2012. Disp.: 〈http://periodicos.letras.ufmg.br/index.php/textolivre>. Acesso: 16 fev. 2016.

DALBERIO, Maria Célia Borges. Políticas educacionais e a gestão democrática na escola pública de qualidade. São Paulo: Paulus, 2009.

DOWBOR, Ladislau. O que é poder local? São Paulo: Brasiliense, 2008.

Revista Teias v. 18, n. 50, 2017 (Jul./Set.): Conversas sobre formação de professores, práticas e currículos 
DURLI, Zenilde; COSTA, Vanessa do Socorro Silva; SANCHES, Ana Lúcia. Um olhar sobre o momento atual da educação brasileira: Entrevista Com Carlos Roberto Jamil Cury. 2009. Disp.: http://revistas.pucsp.br/index.php/ curriculum. Acesso em 30/01/2016.

FERREIRA, Maria Fernanda. O universo das crianças na mídia digital: a experiência de blogs. SIMPÓSIO DE COMUNICAÇÃO E TECNOLOGIAS INTERATIVAS. Anais.... 2009. Disp.: <http://www2.faac.unesp.br/pesquisa/ lecotec/eventos/simposio/anais.html>. Acesso em 03 de setembro de 2015.

FREIRE, Paulo. Pedagogia da Autonomia: saberes necessários à prática educativa. São Paulo/SP, Paz e Terra, 1997.

Pedagogia do Oprimido. 32 ed. São Paulo: Paz e Terra, 2002.

FREITAS, Maria Teresa. Letramento Digital E Formação De Professores. Educação em Revista, Belo Horizonte, v. 26, n. 03, dez. 2010. Disp.: 〈http://www.scielo.br/pdf/edur/v26n3/v26n3a17.pdf>. Acesso em: 14 fev. 2016.

FORQUIN, Jean-Claude. Escola e cultura: as bases sociais e epistemológicas do conhecimento escolar. Porto Alegre: Artes Médicas, 1999.

GADOTTI, Moacir. A escola e o professor: Paulo Freire e a paixão de ensinar . São Paulo: Publisher Brasil, 2007.

GUARESCHI, Pedrinho A.; BIZ, Osvaldo. Mídia educação e cidadania: Tudo o que você deve saber sobre mídia. 2. ed. Petrópolis, RJ,: Vozes, 2006.

LANKSHEAR, C.; SNYDER, I. GREEN, B. Teachers and Technoliteracy, managing literacy, technology and learning in schools. Trad.: St. Leonards. NSW, Australia: Allen \&Unwin, 2000.

LÉVY, Pierre. Cibercultura.Trad.: Carlos Irineu da Costa. 3. ed. São Paulo: Editora 34, 2010.

LUCAS, Maria Angélica Olivo Francisco. Educação Infantil: algumas reflexões sobre seus fundamentos teóricos e metodológicos. Revista HISTEDBR [On-line], Campinas, n.17, p. 79 - 90, mar. 2005. ISSN: 1676-2584.

MACEDO, Elizabeth. Currículo e conhecimento: aproximações entre educação e ensino. Cadernos de Pesquisa, 42(3), p. 716-737, 2012

MAgalhães, Cláudio M. Do Pocinho ao Cabeças: A televisão pelo olhar das crianças de Ouro Preto.Tese (D Doutorado em Educação) - FaE/UFMG, Belo Horizonte, 2007. Disp.: <http://www.bibliotecadigital.ufmg.br/dspace/ bitstream/handle/1843/FAEC-857NFJ/tese_completa_cl_udio_m_rcio_magalh_es.pdf?sequence=1>. Acesso em: 08 jan. 2015.

MANACORDA, Mario Alighiero. História da Educação: da antiguidade aos nossos dias. Trad.: Gaetano Monaco. 13. ed. São Paulo: Cortez Editora, 2010.

MARCíLIO, Maria Luiza. A roda dos expostos e a criança abandonada na História do Brasil: 1726-1950. In: FREITAS, Marcos César. (Org.). História Social da Infância no Brasil. 8. ed. SP: Cortez, 2011. p. 53-80.

MELO, José M. TOSTA, Sandra P. Mídia e Educação. Belo Horizonte: Ed. Autêntica, 2008.

MORAES, M.C. O paradigma educacional emergente. Campinas - SP: Papirus (2003).

NEVES, Angela B. ZAMPERETTI, Maristani P. Artes visuais, tecnologia e educação: experiências pedagógicas com o retroprojetor na sala de aula. Revista Momento Diálogos em Educação, Rio Grande, 19 (2): 9-22, 2010. Disp.: <https://www.seer.furg.br/momento/article/view/1421/1108>. Acesso em 25/04/2016.

PRENSKY, Marc. Digital Natives, Digital Immigrants. MCB University Press, 2001. Disp.: <http://www. marcprensky.com/writing/Prensky\%20-\%20Digital\%20Natives,\%20Digital\%20Immigrants\%20-\%20Part1.pdf >. Acesso em 24 jan. 2016.

PROTÁSIO, Michelle R. ALBUQUERQUE, Simone S. Quando as crianças passam a ser alunas? Problematizações sobre a articulação da educação infantil e os anos iniciais do ensino fundamental. Revista Momento Diálogos em Educação, Rio Grande, 17: 95-106, 2004/2005. Disp.: 〈http://www.seer.furg.br/momento/article/view/615/161〉. Acesso em 27 abr. 2016.

ROCHA, José F. Teles. Do asilo dos expostos ao berçário: assistência e proteção à criança abandonada na cidade de S.P. (1896-1936). Tese (Doutorado em Educação) - Universidade Estadual de Campinas. 2010.

SACRISTÁN J. O currículo: os conteúdos do ensino ou uma análise prática. In: ; PÉREZ GÓMEZ, A. I. Compreender e transformar o ensino. 4. ed. Porto Alegre: ArtMed, 2000.

SANTOS, Gilberto Lacerda. Tablets, laptops, computadores e crianças pequenas: novas linguagens, velhas situações na educação infantil. Brasília : Uber Livros, 2012. 
SILVA, Isa F.R. O processo de constituição das políticas públicas em educação infantil em Belo Horizonte: 1993 a 2000. Dissertação (Mestrado em Educação) - UFMG, Belo Horizonte, 2002.

SOARES, M. Novas práticas de leitura e escrita: letramento na cibercultura. Revista Educação e Sociedade, Campinas, v. 23, n. 81, dez. 2002. Disp.: 〈http://www.scielo.br/pdf/es/v23n81/13935.pdf〉. Acesso: 14 fev. 2016.

SOUZA, V. Soares. Letramento digital e formação de professores. Revista Língua Escrita, n. 2, dez. 2007. Disp.: <http://www.ceale.fae.ufmg.br/app/webroot/files/uploads/revista\%20lingua\%20escrita/LinguaEscrita_2.pdf >. Acesso em 14 fev. 2016.

VIGOTSKI, L.S. A Formação social da mente. São Paulo: Martins Fontes, 2002. 


\section{RESUMO}

É possível interagir mídias digitais com a Educação Infantil? O presente artigo tem por objetivo discutir e problematizar à utilização das mídias digitais nas práticas educativas direcionadas a esse segmento. Analisouse de quais maneiras as mídias podem ser incluídas nas propostas pedagógicas das instituições educativas, de forma a viabilizar a articulação entre tecnologias e práticas de ensino. Para tanto, utilizou-se a pesquisa bibliográfica e documental, a partir do levantamento de textos acadêmicos e análise de leis e documentos sobre as políticas públicas voltadas para a Educação Infantil no Brasil e no município de Belo Horizonte. As principais conclusões apontam possíveis caminhos para a reflexão dos temas abordados. Acredita-se que, dessa maneira, iniciam-se rupturas, reflexões, novas práticas educativas e, enfim, o diálogo com a linguagem digital.

Palavras-chave: Educação Infantil. Currículo. Linguagem Digital. Mídias Digitais.

\section{CHILDREN EDUCATION, DIGITAL MEDIA AND EDUCATIONAL PRACTICES: CROSSED PATHS, POSSIBLE DIALOGS. \\ ABSTRACT}

It is possible to interact with digital media early childhood education? Small children must be presented to media devices at school? This article aims to discuss and discuss the use of digital media in educational practices targeted to that segment. We analyzed what ways the media may be included in the educational proposals of educational institutions, in order to facilitate the articulation between technology and teaching practices. Therefore, we used the bibliographical and documental research. Academic texts were taken in consideration as well as documents and law analysis on the public policies for Children Education in Brazil, specifically in the city of Belo Horizonte. The main conclusions indicate possible reflections of the topics discussed. It is believed that in this way, begin ruptures, reflections, new educational practices and, finally, the dialogue with the digital language.

Keywords: Children Education. Curriculum. Digital language. Digital Media.

\section{EDUCACIÓN INFANTIL, MEDIOS DIGITALES Y PRÁCTICAS EDUCATIVAS: CAMINOS QUE SE CRUZAN, POSIBLES DIÁLOGOS. \\ RESUME}

¿Es posible interactuar los medios digitales con la educación Infantil? Este artículo tiene como objetivo discutir y cuestionar el uso de los medios digitales en las prácticas educativas dirigidas a este segmento. Analizó de qué manera los medios de comunicación pueden ser incluidos en las propuestas educativas de las instituciones educativas, con el fin de facilitar la relación entre la tecnología y las prácticas de enseñanza. Para ello, se utilizó la investigación bibliográfica y documental, basado en una encuesta de textos y análisis de las leyes y documentos académicos sobre políticas públicas para la Educación Infantil en Brasil y en la ciudad de Belo Horizonte. Las principales conclusiones indican posibles vías para la reflexión de los temas abordados. Se cree que de esta manera comenzar a interrupciones, reflexiones, nuevas prácticas educativas y, por último, el diálogo con el lenguaje digital.

Palabras clave: Educación infantil. Plan de estudios. Lenguaje digital. Medios digitales

Submetido em Dez./2016

Aceito em Mai./ 2017

Revista Teias v. 18, n. 50, 2017 (Jul./Set.): Conversas sobre formação de professores, práticas e currículos 